\title{
An Enhanced Software Project Management Methodology Accompanying Agile and CMMI
}

\author{
Hannan Bin Liaqat, M. Rizwan Jameel Qureshi, and Muhammad Shahid
}

\begin{abstract}
The Software Engineering Institute (SEI) has conducted extensive research on improving the quality of software development process. Project management (PM) is an important part in software development organizations. Without proper software project management, it can lead to the failure of software projects. Many software projects are failed to implement the required functionality within schedule and budget. Agile process models emphasize on rapid development. These models have gained great popularity in software development community. One area, often under estimated but crucial, for every software development project, is its management. The major problem with the characteristics of Capability Maturity Model Integration (CMMI) is that it does not make any contribution to the productivity of individual engineers. This paper defines when to implement agile models using CMMI to reduce the failure of software projects
\end{abstract}

Index Terms-PM, CMMI, KPA.

\section{INTRODUCTION}

Software project management uses different tools and techniques to manage software. Project management is a professional technique to show that how to start the project and closing project and how to plan monitor it.

Software development maturity model shows how to control, plan the software development processes to develop high quality software and make much more profit in the market. Maturity model in software industry helps the project managers and high-level managers to assess their project management practices and measure their effectiveness. The (PM) model aims to integrate previous PM practices, processes, and maturity models to improve PM effectiveness in the organization.

The Software Engineering Institute has conducted extensive research on improving the quality of the software development process. As a result, the capability maturity model was developed as a progressive standard to help an organization continuously improve its software processes. In the engineering and construction industry, technology maturity model scenarios were proposed, which had adapt the capability maturity model to explain the incremental use of information technology. Various PM maturity models have been introduced to improve organizations PM effectiveness.

Manuscript received September 7, 2012; revised October 25, 2012. This work was supported in part by the COMSATS Institute of Information Technology Lahore Campus, An Enhanced Software Project Management Methodology Accompanying Agile and CMMI.

The authors are with the COMSATS Institute of Information Technology, Lahore, Pakistan (e-mail: hannanliaqat@hotmail.com, rjamil@ciitlahore.edu.pk, sbhatti@ciitlahore.edu.pk).

\section{RELATED WORK}

CMMI-DEV, CMMI for Development [1] CMM focuses on management activities. It does not say much about how to write Better code. This is unfortunate, since good code is the goal of software development. CMM does not help at all for projects that are in a crisis right now. In addition, this is often when companies look for help with their software process.

A very few software companies follow the CMM, and use their own models for developing processes. Although all of the organizations have various opinions on how to model their processes, the commonality of them is that they do in fact model their processes. Whether or not the CMM is right for them depends on their philosophy of how software should be developed.

In [2] the software process for both management and engineering activities is documented, standardized, and integrated into a standard software process for the organization. All projects use an approved, tailored version of the organization's standard software process for developing and maintaining software. Key process area (KPA) identifies a cluster of related activities that, when performed collectively, achieve a set of goals considered important for enhancing process capability. But if an organization follows it for its own sake rather than simply as a requirement authorization by a particular government contract it may very well lead to the collapse of that company's competitive potential. CMMI should be implemented only on that area in which the company is lacking in their field. CMMI in software industry can only be implemented in key Processes Areas.

The goals of a key process area (KPA) [3] summarize the states that must exist for that key process area to have been implemented in an effective and lasting way. The extent to which the goals have been accomplished is an indicator of how much capability the organization has established at that maturity level.

The goals signify the scope, boundaries, and intent of each key process area [2], [3]. But it has no formal theoretical basis, wastage of time, wastage of resources and it does Contains very little information on process dynamics. Define KPAs and apply it on only these KPAs so that you could get more advantage form CMMI.

In [4], these appear like very ruthless words from one person but he described some general problems that he had encountered during his experiences with the CMM. Without going into specific detail on these problems, Bach disagree the CMM's faults. He even goes as far as to saying that the CMM framework does not allow modernization in an organization. He writes, "Our emphasis is on systematic problem-solving leadership to enable innovation, rather than 
mere process control to enable cookie-cutter solution.” Furthermore, he suggests various alternatives to the model. CMMI models can provide direction, without permitting a particular shape to the organization. However, he also explains that these models are more difficult and thus less marketable so there must be some mechanism where these models can be implemented. To use CMM, You have to think, be flexible, be creative, and integrate the goals of CMM with the Realities of the business.

The maturity levels [5] represent a layered framework providing a progression to the discipline needed to keep continuous improvement. At Initial stages, the software process is characterized as unplanned, and occasionally even disordered. Few processes are defined, and success depends on individual effort and heroics. Basic project management processes are established to track cost, schedule, and functionality. The necessary process discipline is in place to repeat earlier successes on projects with similar applications. But CMM does not make any contribute to the productivity of individual engineers (Software, Quality). CMM is a particular mythology of software process evolution so it cannot correctly declare to be essential representation of software processes. CMMI can potentially valuable for those companies that completely lack software sense or for those who have a lot of it and thus can avoid its drawback. CMM can be at best an agreement among a particular group of software engineering and practitioners regarding a collection of effective practices grouped according to a simple model of organizational evolution.

The Repeatable Level of the CMM [6] gets very involved with producing plans, defining and maintaining metrics such as size and time, and adhering to various software developments standards prescribed by organizations such as IEEE and ACM. However, SEI explains that all of the above KPA must be achieved and maintained in order for a software organization to be considered a Level 2 success, and be allowed to begin Level 3 key process areas. This Encourages displacement of goals from the true mission of improving process to the artificial mission of achieving a higher maturity level. The CMM is simply a guide to help organizations acknowledge their present situation in development. It allows them to concretely view their own work habits to such an abstract concept software development, and adjust them accordingly. Finally, CMM may not work for everyone, but it is important for a project manager to understand where and how projects are being done, and whether or not they are being done properly

In his, Quality Software Management series [7], Gerald Weinberg describes a model based on patterns of human behavior as different to the concept of maturity as applied to software processes. He models these software processes as interactions between humans, and an evolution of problemsolving leadership. Moreover, Capers Jones's book, assessment and Control of Software Risks, discusses the author's model, Software Productivity Research (SPR), which competes with CMM. Jones argues that CMM ignores factors that contribute to the productivity of individual engineers. CMM does not help at all for projects that are in a crisis right now. In addition, this is often when companies look for help with their software process. It appears to me that the CMM is a philosophy and not a standard. In other words, it is not an answer for organizations; it does not provide them steps to be the best in the industry. So, whether it is the CMM or an alternative model be used to maintain data, a project manager must be able to predict project metrics (i.e. schedules, budget, size, etc.)

Bach [8] writes the Following at the beginning of his article: "The CMM is a particular mythology of software process evolution that cannot rightfully claim to be a natural or essential representation of software processes. The CMM is at best an agreement among a particular group of software engineering theorists and practitioners regarding a collection of effective practices grouped according to a simple model of organizational evolution. As such, it is potentially valuable for those companies that completely lack software savvy or for those who have a lot of it and thus can avoid its pitfall. At worst the CMM is a reverse that unclear the true dynamics of software engineering, contain alternative models. If an organization follows, it for its own sake rather than simply as a requirement authorization by a particular government contract it may very well lead to the collapse of that company's competitive potential. For these reasons, the CMM is unpopular among many of the highly competitive and innovative companies producing commercial minimize wrap software”. Organizations are using CMM as a stamp of approval, without really committing to Process improvement. They want to find the easiest way to get certified as Level 2 Without really changing their underlying methods. Process should be simple and effective so that it could not need for any level of maturity. It should be affective enough for the development of Product.

A Very few organizations have achieved the level 5 rating of the CMM. In fact, NASA is one of those organizations [9]. However, even those organizations that have not reached level 5 have achieved a great deal of pride for all of the work in reaching levels 2 and 3 . For example, EDS - Applied Engineering Solutions achieved a level 3 rating in January 2001.

The division vice president, Tom Brady, quotes: "We worked diligently for more than 20 months to earn this prestigious distinction. Only NASA has achieved Level 5, so we consider the embedded solutions group a real Asset to EDS - AES and our clients. Reaching this level of software engineering Expertise contributes to our commitment to move our clients faster to market.” In July 1996, the Boeing Defense and Space Group, Boeing Space Transportation system (STS), achieved a Level 5 rating in the CMM [8]. This success was derived from data captured in a process library that contained over 15 years worth of process-related data to review. The program used, maintained, and improved years of process data and measurements. Additionally, they demonstrated their capability to continuously improve processes. CMM is a reverse that unclear the true dynamics of software engineering, contain alternative models. CMM without KPAs is useless so there must be some mechanism to define KPAs pf an organization.

Dean A. Leffingwell, [10] of Rational, wrote the following in support of the CMM: "The CMM provides a 
comprehensive view of the activities which must be applied to improve software quality and increase productivity. Requirements Management is an Integral part of this process wherein requirements serve as living entities which are at the center of development activity [8], [9], [10]. Once elicited, requirements are documented and Managed with the same degree of care that we provide to our code work products. This process puts the team in control of their project and helps them manage both the project and its scope. Lastly, actively managing changing requirements keeps the project under Control and helps assure the reliable, repeatable production of high quality software products.” It contains very little information on process dynamics. Our emphasis should be on systematic problem-solving leadership to enable innovation, rather than mere process control to enable cookie-cutter solution.

\section{Problem Statement}

\author{
"How can Agile\& CMMI leads failing project to \\ successful one?”
}

\section{Detail of Problem in Term of Issue}

In the last years, several companies have started initiatives to improve their software development. These initiatives mostly focus on improving the software processes and the technology used during software development. Agile process model is getting much more importance in the software development activities

Agile process model is rapid development model. One area often underestimated but crucial for every software development project is project management. The major problem with CMM is that it does not make any contribute to the productivity of individual engineers.

Next section we give them a propose solution to solve the problem.

\section{Proposed Solution}

\section{A. Problem Analysis}

In this initial step, we have to identify the problem. We have to check where the problem is resided. Perform deep analysis and see is there anything to change so this step will clear that what we have to do. Problem Identification is major problem in Agile Development. Change needs Management Commitment and involvement of all stakeholders.

\section{B. Define Development Plans}

This step needs to do clear planning and control of CMMI implementation. Your Goal must be clear in order to achieve. In development plan, all the internal stakeholders must be involved. There should be high-level support for change. Change in AGILE is a big deal so it does need high-level permission.

After approval of development plans it should be implemented or prepare for it. Set Action priorities for action

\section{Make Preparation or Development}

The software company wants to develop the proposed solution here they want to implement the only those KPAs where they feel lackness because agile is rapid development so that's why only those fields need changes who perform functionality.

\section{Analysis of Knowledge Competence}

- Knowledge Competence: This is the knowledge that Project Managers bring to project. It depends on PM personal experience. If he/she is well experienced then the level of knowledge competence will be high and will be use full for the project.

- Project Manager Competence Behavior: The ability to perform project management activity to certain level for special projects.

- PM Personal Behavior: Project manager's Personal behavior with his team has much importance so his behavior with other employees, Helping each other, managerial skills, and his personal effectiveness does count.

- Individual Team Member: The combined competency level of individual member, Development, Quality Analysis, Configuration. Testing and Planning.

- Project Performance: A measure of context to which the project is developed as planned in terms of goals, time, financial. Organizational policy and procedure

\section{E. Analyze Results}

After develop the project or implement it we analyze the results of the project what behavior they adopt and what performance they give in agile If our results are not given the proper output we use the CMMI level. CMMI level is the management activity in which tell that how to start the project in CMMI many levels are define level 1 is initial level and level 2 is management activity we adopt some phases level 2 is used for management activities
1) Proper Requirement Gathering
2) Requirement management
3) Project Planning
4) Project monitoring and controls

\section{F. Reschedule}

Rescheduling phase is used when you give them proper solution but here we reschedule only those activities that are key process area the main function where our projects are fails because when we analyze here our project is fail we planned again so that's why we reschedule our projects.

\section{VALidATION OF THE PROPOSED SOLUTION}

Validation of proposed solution is conducting a survey through the questioner. The purpose of adopting this method is it's not too much time consuming and the person who fills the questioner have lot of time and give them answer through a thoughtful way. So that's why validation of proposed solution is approved by questioner. 


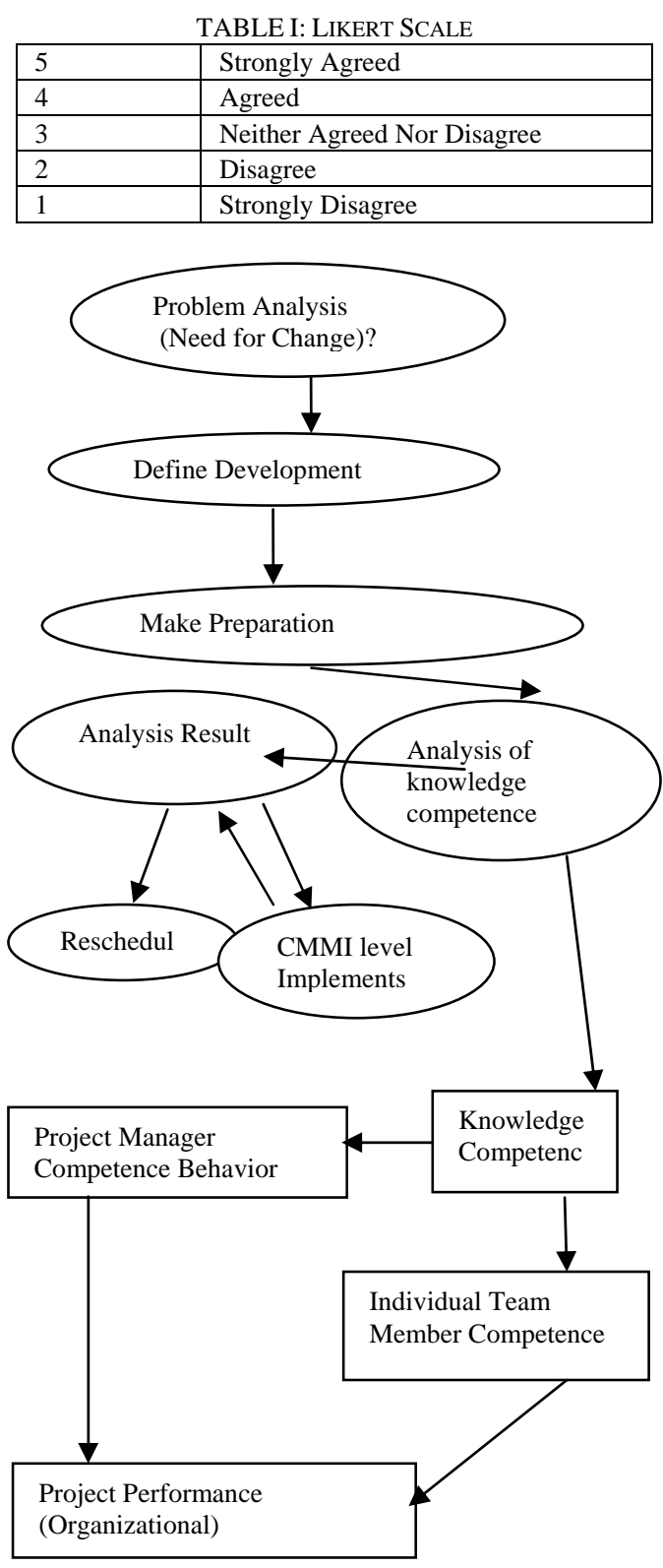

Fig. 1. Diagram of Proposed Solution

\section{A. Validation Using Survey}

Goals of proposed solution we developed a comprehensive questionnaire comprising of 20 closed ended questions. In order to validate the questionnaire it is circulated through the software industry. As for as its response is concerned we get it from soft ware industry of Pakistan including Net Sol Technologies, Flying Group of companies, CMIT and filled with different software houses

Statistical analysis is made based on gathered data through the distribution of questionnaire. The analysis form is represented through frequency tables and bar charts showing the exact degree of analysis. We describe the validation results based on our results below.

Goal: 1 Management Problem can be faced in AGILE model while implementing CMMI.

Goal: 1

Question1 shows how much length of the project. As far as graphical representation shows the same behavior that out of 27 populations of $7.4 \%$ strongly agreed, $55.6 \%$ agreed where as $22.2 \%$ neither agreed nor disagree from the proposed statement. And 14.8\%are disagreeing.

\begin{tabular}{|c|c|c|c|c|c|}
\hline & & Frequency & Percent & Valid Percent & $\begin{array}{c}\text { Cumulative } \\
\text { Percent }\end{array}$ \\
\hline \multirow[t]{5}{*}{ Valid } & 2.00 & 4 & 14.8 & 14.8 & 14.8 \\
\hline & 3.00 & 6 & 22.2 & 22.2 & 37.0 \\
\hline & 4.00 & 15 & 55.6 & 55.6 & 92.6 \\
\hline & 5.00 & 2 & 7.4 & 7.4 & 100.0 \\
\hline & Total & 27 & 100.0 & 100.0 & \\
\hline
\end{tabular}

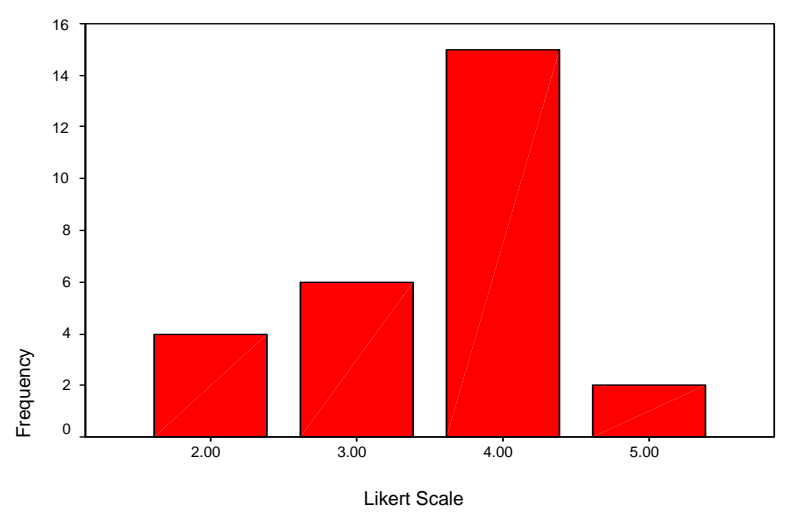

Fig. 2. Graphical representation of question 1

Goal: 1

Question-2 we develop the Agile model with CMMI so we analyze how many people's are required. The reply through the frequency table shows out of 27 questionnaires, $7.4 \%$ strongly agreed, $55.6 \%$ agreed where as $22.2 \%$ neither agreed nor disagree from the proposed statement. And 14.8\%are disagreeing.

\begin{tabular}{|c|c|c|c|c|c|}
\hline & & Frequency & Percent & Valid Percent & $\begin{array}{c}\text { Cumulative } \\
\text { Percent }\end{array}$ \\
\hline \multirow[t]{6}{*}{$\overline{\text { Valid }}$} & 1.00 & 2 & 7.4 & 7.4 & 7.4 \\
\hline & 2.00 & 3 & 11.1 & 11.1 & 18.5 \\
\hline & 3.00 & 9 & 33.3 & 33.3 & 51.9 \\
\hline & 4.00 & 11 & 40.7 & 40.7 & 92.6 \\
\hline & 5.00 & 2 & 7.4 & 7.4 & 100.0 \\
\hline & Total & 27 & 100.0 & 100.0 & \\
\hline
\end{tabular}

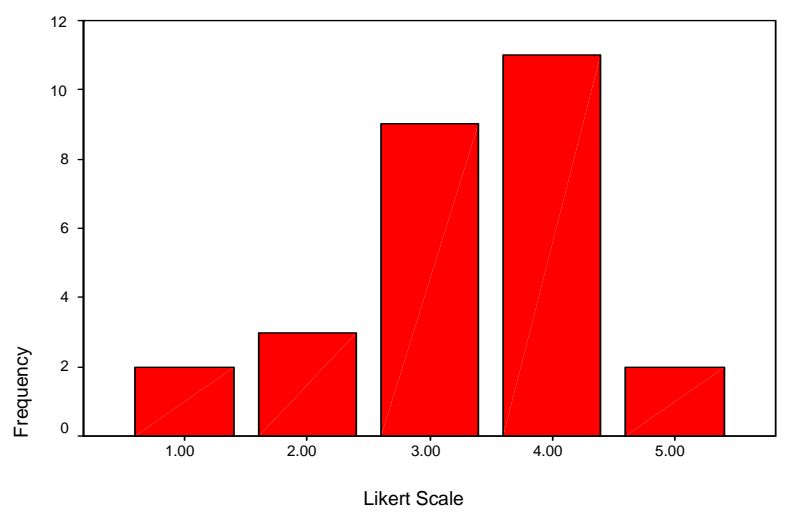

Fig. 3. Graphical representation of question 2

Goal: 1

In question-3 we analyze that CMMI helps to manage the project management activity. The reply through the frequency table shows out of 27 questionnaires, $37 \%$ strongly agreed, $48.1 \%$ agreed where as $3.7 \%$ neither agreed nor disagree from the proposed statement. And $11.1 \%$ are disagreeing. 
TABLE IV: FREQUENCY CHART

\begin{tabular}{|rr|r|r|r|r|}
\hline & & & & & Cumulative \\
& & Frequency & Percent & Valid Percent & \multicolumn{1}{c|}{ Percent } \\
\hline Valid & 2.00 & 3 & 11.1 & 11.1 & 11.1 \\
& 3.00 & 1 & 3.7 & 3.7 & 14.8 \\
& 13 & 48.1 & 48.1 & 63.0 \\
& 5.00 & 10 & 37.0 & 37.0 & 100.0 \\
& Total & 27 & 100.0 & 100.0 & \\
\hline
\end{tabular}

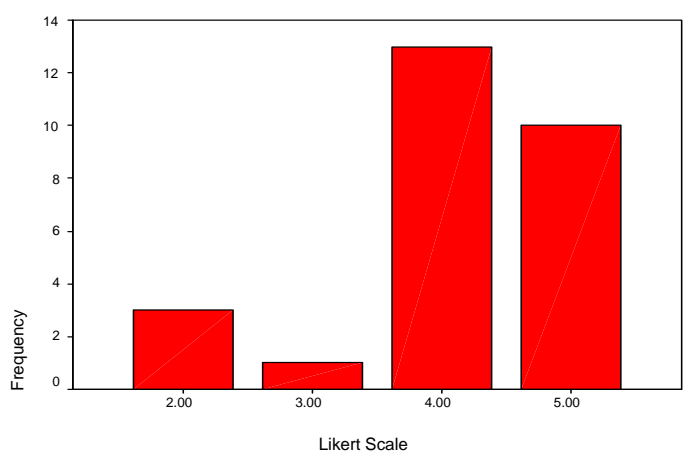

Fig. 4. Graphical representation of question 3

Goal: 1

Question-4 we want to see that is one project manager is enough to handle the project. The reply through the frequency table shows out of 27 questionnaires, $3.7 \%$ strongly agreed, $37.0 \%$ agreed where as $33.3 \%$ neither agreed nor disagree from the proposed statement. And 25.9\%are disagreeing.

\begin{tabular}{|c|c|c|c|c|c|}
\hline & & Frequency & Percent & Valid Percent & $\begin{array}{c}\text { Cumulative } \\
\text { Percent }\end{array}$ \\
\hline \multirow[t]{5}{*}{ Valid } & 2.00 & 7 & 25.9 & 25.9 & 25.9 \\
\hline & 3.00 & 9 & 33.3 & 33.3 & 59.3 \\
\hline & 4.00 & 10 & 37.0 & 37.0 & 96.3 \\
\hline & 5.00 & 1 & 3.7 & 3.7 & 100.0 \\
\hline & Total & 27 & 100.0 & 100.0 & \\
\hline
\end{tabular}

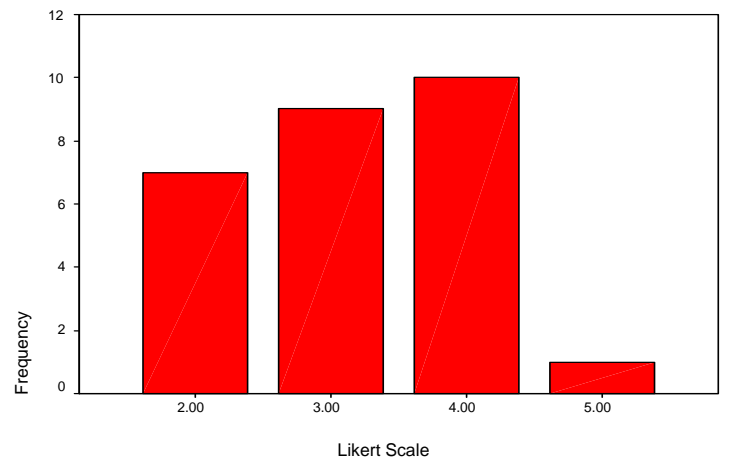

Fig. 5. Graphical representation of question 4

Goal: 1

Question-5 we analyze that spreading knowledge in individual is the best practice to improve the performance of agile model the reply through the frequency table shows out of 27 questionnaires, $11.1 \%$ strongly agreed, $63 \%$ agreed where as $18.5 \%$ neither agreed nor disagree from the proposed statement. And 7.4\%are disagreeing.

\begin{tabular}{|c|c|c|c|c|c|}
\hline & & Frequency & Percent & Valid Percent & $\begin{array}{c}\text { Cumulative } \\
\text { Percent }\end{array}$ \\
\hline \multirow[t]{5}{*}{ Valid } & 2.00 & 2 & 7.4 & 7.4 & 7.4 \\
\hline & 3.00 & 5 & 18.5 & 18.5 & 25.9 \\
\hline & 4.00 & 17 & 63.0 & 63.0 & 88.9 \\
\hline & 5.00 & 3 & 11.1 & 11.1 & 100.0 \\
\hline & Total & 27 & 100.0 & 100.0 & \\
\hline
\end{tabular}

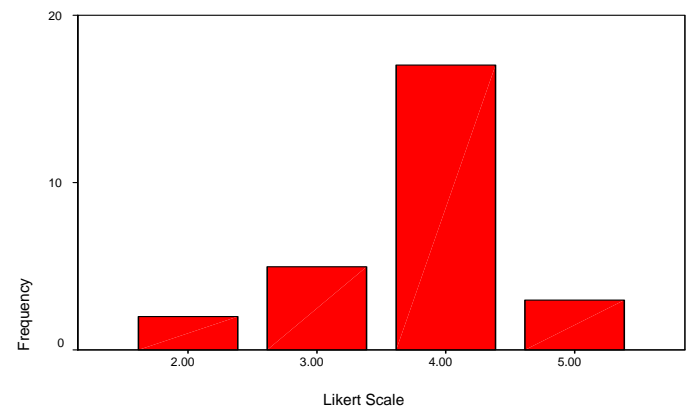

Fig. 6. Graphical representation of question 5

Goal: 2

People/Change Management can be difficult in agile model for implementing CMMI

Question-6 we analyze in the initial level changes is easy to handle. The reply through the frequency table shows out of 27 questionnaires, $29.6 \%$ strongly agreed, $55.6 \%$ agreed where as $7.4 \%$ neither agreed nor disagree from the proposed statement. And 7.4 \%are disagreeing.

TABLE VII: FREQUENCY TABLE

\begin{tabular}{|rr|r|r|r|r|}
\hline & & & & & Cumulative \\
& & Frequency & Percent & Valid Percent & \multicolumn{1}{c|}{ Percent } \\
\hline Valid & 1.00 & 2 & 7.4 & 7.4 & 7.4 \\
& 3.00 & 2 & 7.4 & 7.4 & 14.8 \\
& 4.00 & & 55.6 & 55.6 & 70.4 \\
& 5.00 & 8 & 29.6 & 29.6 & 100.0 \\
& Total & 27 & 100.0 & 100.0 & \\
\hline
\end{tabular}

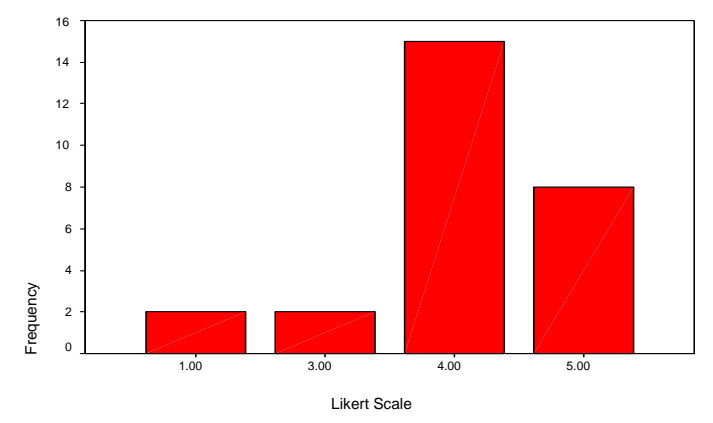

Fig. 7. Graphical representation of question 6.

Goal: 2

Question-7 we analyze in the middle level changes are hard to handle. The reply through the frequency table shows out of 27 questionnaires, $14.8 \%$ strongly agreed, $51.9 \%$ agreed where as $25.9 \%$ neither agreed nor disagree from the proposed statement. And $7.4 \%$ are disagreeing

\begin{tabular}{|c|c|c|c|c|c|}
\hline & & Frequency & Percent & Valid Percent & $\begin{array}{c}\text { Cumulative } \\
\text { Percent }\end{array}$ \\
\hline \multirow[t]{5}{*}{ Valid } & 2.00 & 2 & 7.4 & 7.4 & 7.4 \\
\hline & 3.00 & 7 & 25.9 & 25.9 & 33.3 \\
\hline & 4.00 & 14 & 51.9 & 51.9 & 85.2 \\
\hline & 5.00 & 4 & 14.8 & 14.8 & 100.0 \\
\hline & Total & 27 & 100.0 & 100.0 & \\
\hline
\end{tabular}

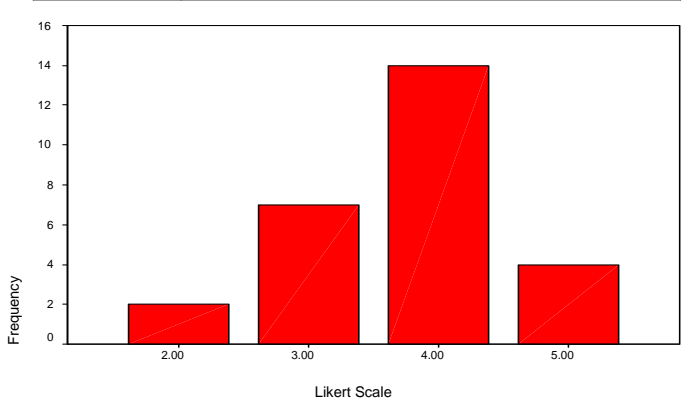

Fig. 8. Graphical representation of question 7 


\section{Goal: 2}

Question-8 we analyze that the project should reschedule when error occurred. The reply through the frequency table shows out of 27 questionnaires, $11.1 \%$ strongly agreed, $33.3 \%$ agreed where as $11.1 \%$ neither agreed nor disagree from the proposed statement. And 44.4 \%are disagreeing.

TABLE IX: FREQUENCY TABLE

\begin{tabular}{|rr|r|r|r|r|}
\hline & & & & & Cumulative \\
Prequency & Percent & Valid Percent & Percent \\
\hline Valid & 2.00 & 12 & 44.4 & 44.4 & 44.4 \\
& 3.00 & 3 & 11.1 & 11.1 & 55.6 \\
& 4.00 & 9 & 33.3 & 33.3 & 88.9 \\
& 5.00 & 3 & 11.1 & 11.1 & 100.0 \\
& Total & 27 & 100.0 & 100.0 & \\
\hline
\end{tabular}

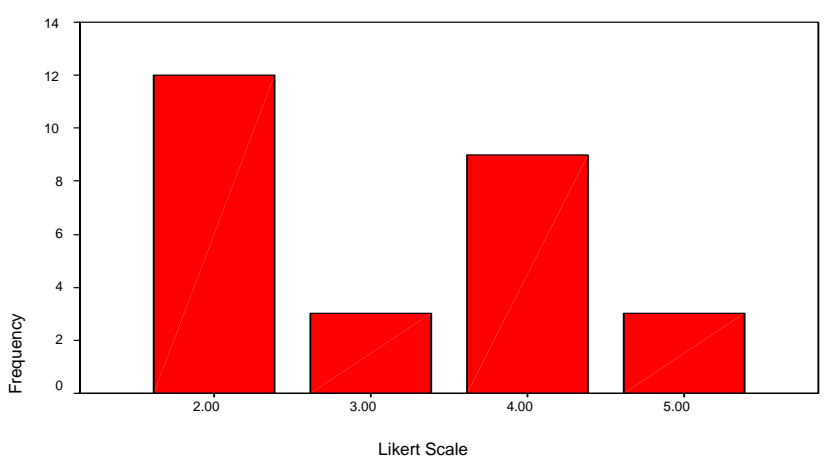

Fig. 9. Graphical representation of question 8

Goal: 2

Question-9 should we change development plan after remedy. The reply through the frequency table shows out of 27 questionnaires, $7.4 \%$ strongly agreed, $40.7 \%$ agreed where as $37.0 \%$ neither agreed nor disagree from the proposed statement. And $14.8 \%$ are disagreeing.

TABLE X: FREQUENCY TABLE

\begin{tabular}{|rr|r|r|r|r|}
\hline & & Frequency & Percent & Valid Percent & $\begin{array}{c}\text { Cumulative } \\
\text { Percent }\end{array}$ \\
\hline Valid & 2.00 & 4 & 14.8 & 14.8 & 14.8 \\
& 3.00 & 10 & 37.0 & 37.0 & 51.9 \\
& 4.00 & 11 & 40.7 & 40.7 & 92.6 \\
& 5.00 & 2 & 7.4 & 7.4 & 100.0 \\
& Total & 27 & 100.0 & 100.0 & \\
\hline
\end{tabular}

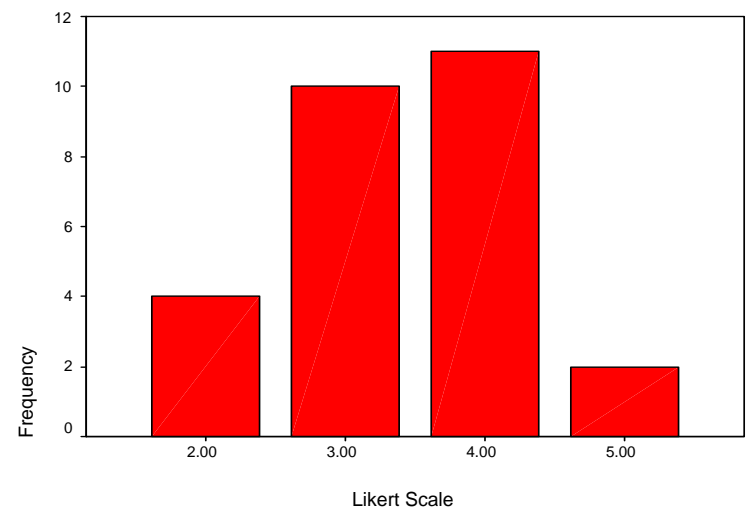

Fig. 10. Graphical representation of question 9

Goal: 2

Question-10 thorough analysis required to find problem. The reply through the frequency table shows out of 27 questionnaires, 37. \% strongly agreed, $44.4 \%$ agreed where as $18.5 \%$ neither agreed nor disagree from the proposed statement. And neither one is disagree for this statement.
TABLE XI: FREQUENCY TABLE

\begin{tabular}{|rr|r|r|r|r|}
\hline & & & & & \multicolumn{1}{c|}{$\begin{array}{c}\text { Cumulative } \\
\text { Percent }\end{array}$} \\
\hline Valid & 3.00 & 5 & 18.5 & 18.5 & 18.5 \\
& 4.00 & 12 & 44.4 & 44.4 & 63.0 \\
& 5.00 & 10 & 37.0 & 37.0 & 100.0 \\
& Total & 27 & 100.0 & 100.0 & \\
\hline
\end{tabular}

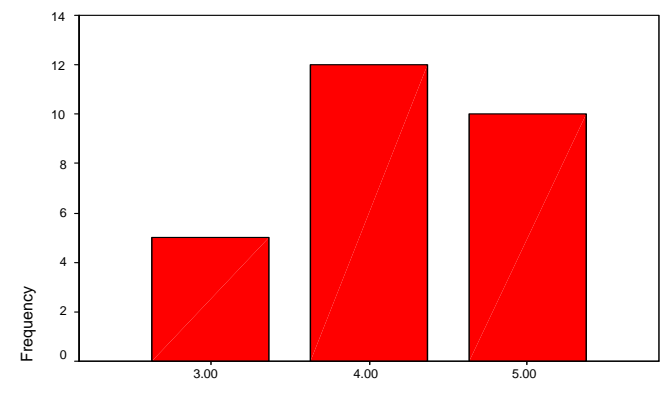

Likert Scale

Fig. 11. Graphical representation of question 10

Goal: 3

KPAS are the most important thing in CMMI but it does not cover major part of Agile and CMMI implementation Steps. KPA's can not specify for certain model and procedure

\section{Goal: 3}

Question-11 CMMI in Agile always focuses on KPA's to improve project with in limited time. The reply through the frequency table shows out of 27 questionnaires, $14.8 \%$ strongly agreed, $40.7 \%$ agreed where as $33.3 \%$ neither agreed nor disagree from the proposed statement. And $3.7 \%$ are disagreed $7.4 \%$ peoples are strongly disagreed.

\begin{tabular}{|c|c|c|c|c|c|}
\hline & & Frequency & Percent & Valid Percent & $\begin{array}{c}\text { Cumulative } \\
\text { Percent }\end{array}$ \\
\hline \multirow[t]{6}{*}{ Valid } & 1.00 & 2 & $\overline{7.4}$ & 7.4 & 7.4 \\
\hline & 2.00 & 1 & 3.7 & 3.7 & 11.1 \\
\hline & 3.00 & 9 & 33.3 & 33.3 & 44.4 \\
\hline & 4.00 & 11 & 40.7 & 40.7 & 85.2 \\
\hline & 5.00 & 4 & 14.8 & 14.8 & 100.0 \\
\hline & Total & 27 & 100.0 & 100.0 & \\
\hline
\end{tabular}

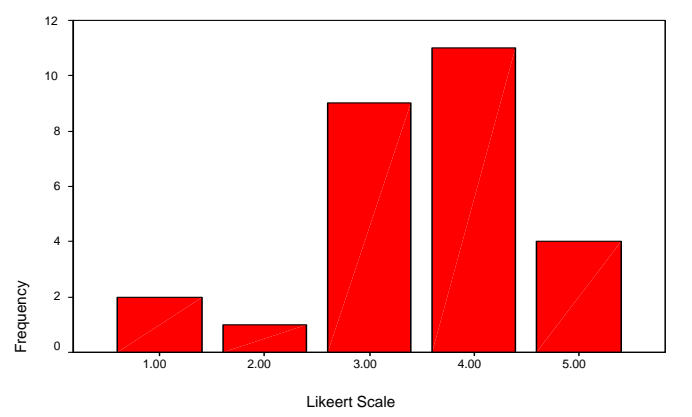

Fig. 12. Graphical representation of question 11

Goal:3

Question-12 CMMI with Agile to improve the quality. The reply through the frequency table shows out of 27 questionnaires, $59.3 \%$ agreed where as $33.3 \%$ neither agreed nor disagree from the proposed statement. And $7.4 \%$ are disagreed

\begin{tabular}{|c|c|c|c|c|c|}
\hline & & Frequency & Percent & Valid Percent & $\begin{array}{c}\text { Cumulative } \\
\text { Percent }\end{array}$ \\
\hline \multirow[t]{4}{*}{ Valid } & 2.00 & 2 & 7.4 & 7.4 & 7.4 \\
\hline & 3.00 & 9 & 33.3 & 33.3 & 40.7 \\
\hline & 4.00 & 16 & 59.3 & 59.3 & 100.0 \\
\hline & Total & 27 & 100.0 & 100.0 & \\
\hline
\end{tabular}




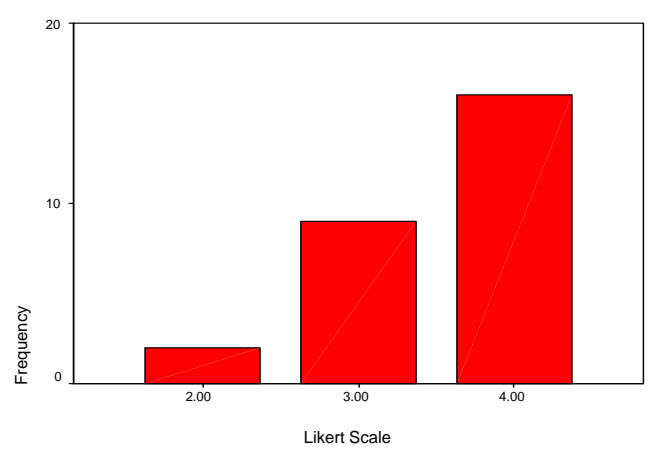

Fig. 13. Graphical representation of question 12

Goal: 3

Question-13 CMMI level 2 adopt is the best practice. The reply through the frequency table shows out of 27 questionnaires, $11.1 \%$ strongly agreed, $44.4 \%$ agreed where as $25.9 \%$ neither agreed nor disagree from the proposed statement. And $18.5 \%$ are disagreeing

\begin{tabular}{|c|c|c|c|c|c|}
\hline & & Frequency & Percent & Valid Percent & $\begin{array}{c}\text { Cumulative } \\
\text { Percent }\end{array}$ \\
\hline \multirow[t]{5}{*}{ Valid } & 2.00 & 5 & 18.5 & 18.5 & 18.5 \\
\hline & 3.00 & 7 & 25.9 & 25.9 & 44.4 \\
\hline & 4.00 & 12 & 44.4 & 44.4 & 88.9 \\
\hline & 5.00 & 3 & 11.1 & 11.1 & 100.0 \\
\hline & Total & 27 & 100.0 & 100.0 & \\
\hline
\end{tabular}

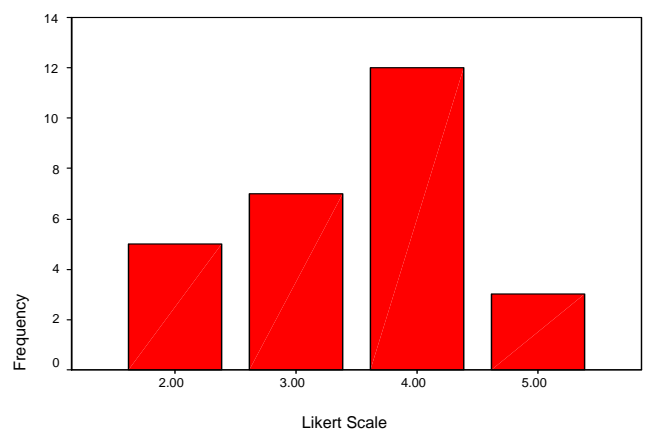

Fig. 14. Graphical representation of question 13

Goal: 3

Question-14 Agile customer involvement is must to complete the project in specific time. The reply through the frequency table shows out of 27 questionnaires, $18.5 \%$ strongly agreed, $55.6 \%$ agreed where as $25.9 \%$ neither agreed nor disagree
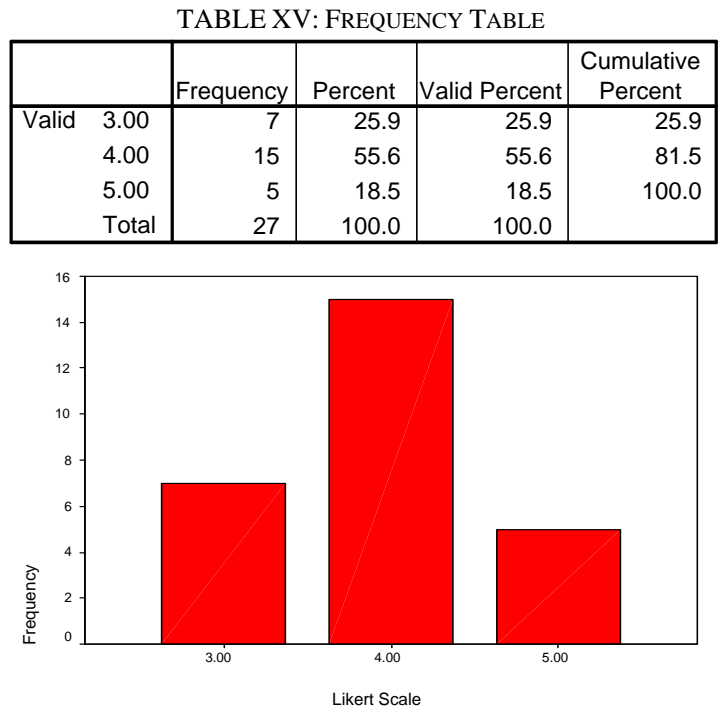

Fig. 15. Graphical representation of question 14
Goal: 3

Question-15 Goal should clear in Agile development method. The reply through the frequency table shows out of 27 questionnaires, $7.4 \%$ strongly agreed, $77.8 \%$ agreed where as $14.8 \%$ neither agreed nor disagree

\begin{tabular}{|c|c|c|c|c|c|}
\hline & & Frequency & Percent & Valid Percent & $\begin{array}{c}\text { Cumulative } \\
\text { Percent }\end{array}$ \\
\hline \multirow[t]{4}{*}{ Valid } & 3.00 & 4 & 14.8 & 14.8 & 14.8 \\
\hline & 4.00 & 21 & 77.8 & 77.8 & 92.6 \\
\hline & 5.00 & 2 & 7.4 & 7.4 & 100.0 \\
\hline & Total & 27 & 100.0 & 100.0 & \\
\hline
\end{tabular}

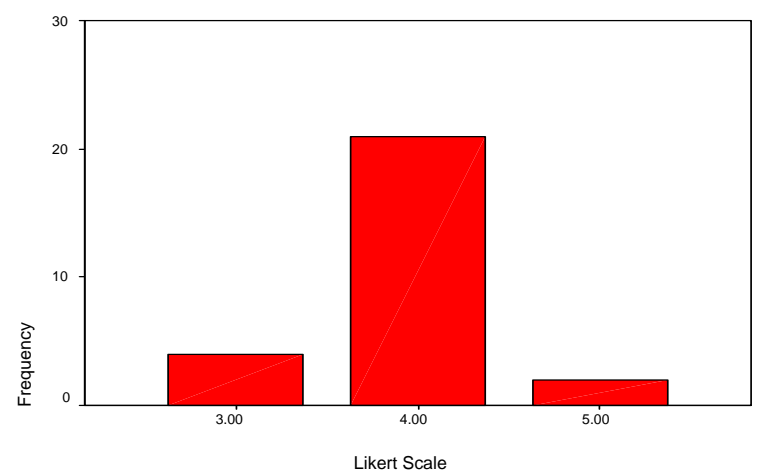

Fig. 16. Graphical representation of question 15

Goal: 4

CMMI does not pay any attention towards the Performance and competence of Individual Engineer Goal: 4

Question-16 we analyze is CMMI helps the developer to develop the tool. The reply through the frequency table shows out of 27 questionnaires, $3.7 \%$ strongly agreed, $22.2 \%$ agreed where as $22.2 \%$ neither agreed nor disagree $29.6 \%$ are disagreed and $22.2 \%$ are strongly disagreed

\begin{tabular}{|c|c|c|c|c|c|}
\hline & & Frequency & Percent & Valid Percent & $\begin{array}{c}\text { Cumulative } \\
\text { Percent }\end{array}$ \\
\hline \multirow[t]{6}{*}{ Valid } & 1.00 & 6 & 22.2 & 22.2 & 22.2 \\
\hline & 2.00 & 8 & 29.6 & 29.6 & 51.9 \\
\hline & 3.00 & 6 & 22.2 & 22.2 & 74.1 \\
\hline & 4.00 & 6 & 22.2 & 22.2 & 96.3 \\
\hline & 5.00 & 1 & 3.7 & 3.7 & 100.0 \\
\hline & Total & 27 & 100.0 & 100.0 & \\
\hline
\end{tabular}

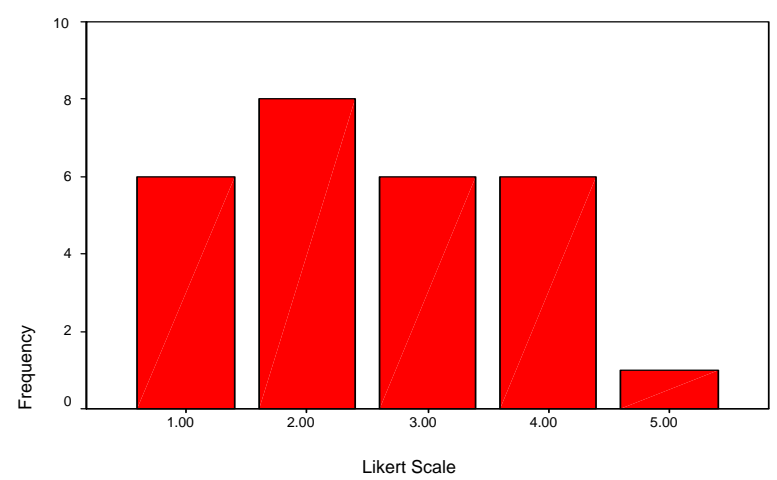

Fig. 17. Graphical representation of question 16

Goal: 4

Question-17 the project manager personal behavior should helpful to complete the project. The reply through the frequency table shows out of 27 questionnaires, $14.8 \%$ strongly agreed, $59.3 \%$ agreed where as $18.5 \%$ neither agreed nor disagree 7.4 \%are disagreed. 
TABLE XVIII: FREQUENCY TABLE

\begin{tabular}{|rr|r|r|r|r|}
\hline & & & & \multicolumn{1}{c|}{$\begin{array}{c}\text { Cumulative } \\
\text { Percent }\end{array}$} \\
\hline Valid & 2.00 & 2 & 7.4 & 7.4 & 7.4 \\
& 3.00 & 5 & 18.5 & 18.5 & 25.9 \\
& 4.00 & 16 & 59.3 & 59.3 & 85.2 \\
& 5.00 & 4 & 14.8 & 14.8 & 100.0 \\
& Total & 27 & 100.0 & 100.0 & \\
\hline
\end{tabular}

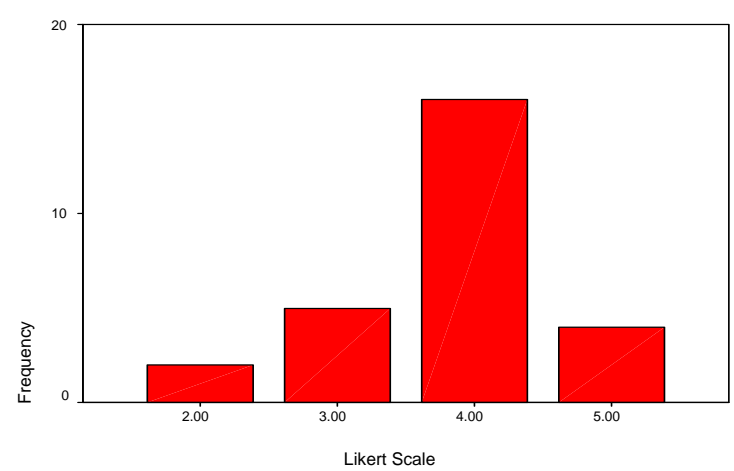

Fig. 18. Graphical representation of question 17

\section{Goal: 4}

Question-18 Agile doesn't give proper solution so that's why use CMMI for managed activity? The reply through the frequency table shows out of 27 questionnaires, $3.7 \%$ strongly agreed, $55.6 \%$ agreed where as $25.9 \%$ neither agreed nor disagree $14.8 \%$ are disagreed.

TABLE XIX: FREQUENCY TABLE

\begin{tabular}{|rr|r|r|r|r|}
\hline & & Frequency & Percent & Valid Percent & $\begin{array}{c}\text { Cumulative } \\
\text { Percent }\end{array}$ \\
\hline Valid & 2.00 & 4 & 14.8 & 14.8 & 14.8 \\
& 3.00 & 7 & 25.9 & 25.9 & 40.7 \\
& 4.00 & 15 & 55.6 & 55.6 & 96.3 \\
& 5.00 & 1 & 3.7 & 3.7 & 100.0 \\
& Total & 27 & 100.0 & 100.0 & \\
\hline
\end{tabular}

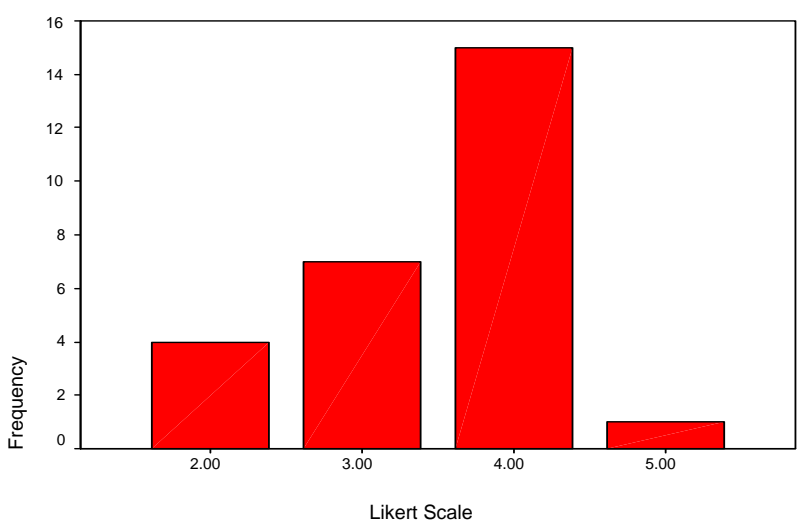

Fig. 19. Graphical representation of question 18

Goal: 4

Question-19 rescheduling must be done after using CMMI level. The reply through the frequency table shows out of 27 questionnaires, $11.1 \%$ strongly agreed, $44.4 \%$ agreed where as $18.5 \%$ neither agreed nor disagree $25.9 \%$ are disagreed

\begin{tabular}{|c|c|c|c|c|c|}
\hline & & Frequency & Percent & Valid Percent & $\begin{array}{c}\text { Cumulative } \\
\text { Percent }\end{array}$ \\
\hline \multirow[t]{5}{*}{ Valid } & 2.00 & 7 & 25.9 & 25.9 & 25.9 \\
\hline & 3.00 & 5 & 18.5 & 18.5 & 44.4 \\
\hline & 4.00 & 12 & 44.4 & 44.4 & 88.9 \\
\hline & 5.00 & 3 & 11.1 & 11.1 & 100.0 \\
\hline & Total & 27 & 100.0 & 100.0 & \\
\hline
\end{tabular}

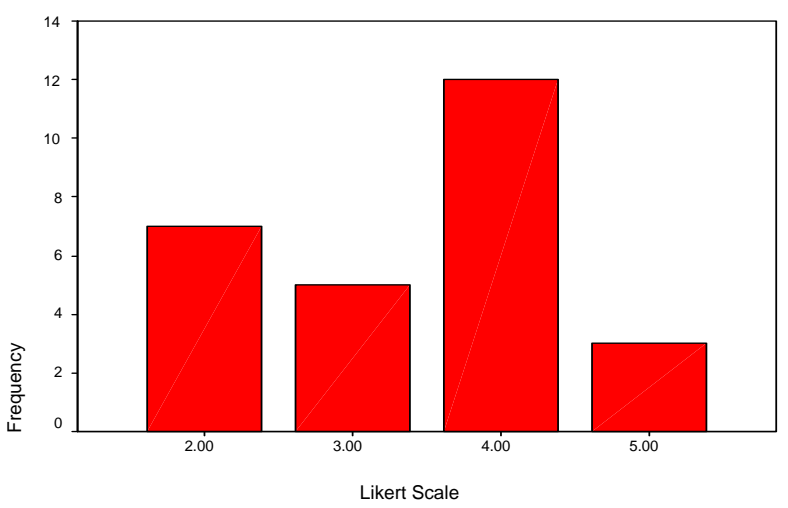

Fig. 20. Graphical representation of question 19

Goal: 4

Question-20 we analyses its compulsory to use all point of CMMI levels The reply through the frequency table shows out of 27 questionnaires, $7.4 \%$ strongly agreed, $44.4 \%$ agreed where as $18.5 \%$ neither agreed nor disagree $22.2 \%$ are disagreed and $7.4 \%$ are strongly disagreed.

\begin{tabular}{|c|c|c|c|c|c|}
\hline & & Frequency & Percent & Valid Percent & $\begin{array}{c}\text { Cumulative } \\
\text { Percent }\end{array}$ \\
\hline \multirow[t]{6}{*}{ Valid } & 1.00 & 2 & 7.4 & 7.4 & $\overline{7.4}$ \\
\hline & 2.00 & 6 & 22.2 & 22.2 & 29.6 \\
\hline & 3.00 & 5 & 18.5 & 18.5 & 48.1 \\
\hline & 4.00 & 12 & 44.4 & 44.4 & 92.6 \\
\hline & 5.00 & 2 & 7.4 & 7.4 & 100.0 \\
\hline & Total & 27 & 100.0 & 100.0 & \\
\hline
\end{tabular}

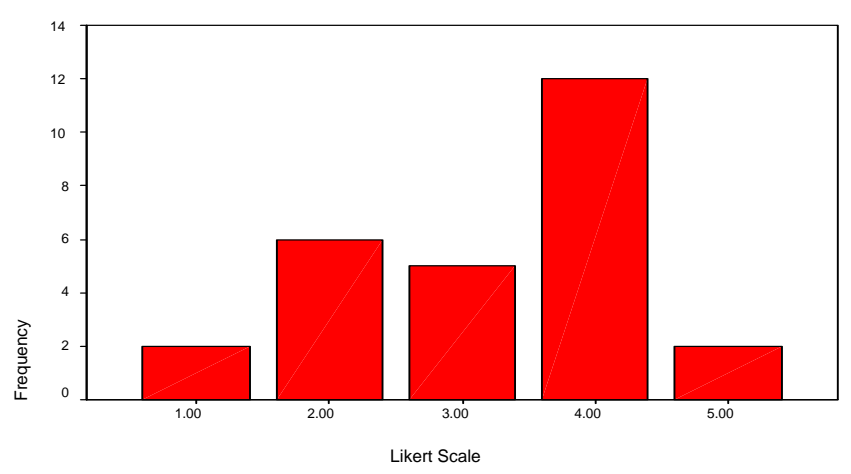

Fig. 21. Graphical representation of question 20

\section{CONCLUSION}

The major advantages of using a Project Management Capability Maturity Model are seen as its objective of measurement criteria and its high degree of repeatability. With Addition to above an effective model carefully applied can gain quick and sustainable

Capability Maturity Model can be found on the shelf from readily-available sources in the literature, a highlyeffective model for application in almost any industrial or technical process and/or organization can be easily designed and implemented, given the excellent tools and reference materials now available. Even better, application of the model and objective presentation of quantifiable and verifiable measurement data to either a receptive management or a grateful client can bring results that would satisfy even the most jaundiced of observers. 


\section{REFERENCES}

[1] CMMI-DEV, CMMI for Development, V1.2 model, CMU/SEI-2006TR-008, Software Engineering Institute, 2006.

[2] D. J. Anderson, "Stretching Agile to fit CMMI Level 3," presented at Agile 2005 Conference, Dever, [Online] Available: http://www.agilemanagement.net/Articles/Papers/Agile_2005_Paper_ DJA_v1_5.pdf , 2005.

[3] K. Beck. et al. Manifesto for agile software development, [Online] Available: http://www. agilemanifesto.org/. (December 2006).

[4] B. Boehm, "A view of 20th and 21st century software engineering," ICSE 2006, May 2006.

[5] G. Alleman, "Blending agile development methods with CMMI," Cutter IT Journal, vol. 17, no. 6, June 2004.

[6] S. P. Mandl and H. Lichter, "A Case study on simulating software projects - An approach for teaching project management," 06. - 08. May 1998, Antwerp, Belgium, 1998, pp $305-313$.

[7] CMMI Product Development Team (2000), CMMI for Systems Engineering/Software Engineering, version 1. 02, CMU/SEI-2000TR-018. Pittsburgh, PA: Software Engineering Institute.

[8] ISO/IECJTC1/WG10, "SPICE Products," Technical Report, Type 2, June 1995.

[9] A. Dorling, "SPICE: software process improvement and capability determination,” Software Quality Journal 2, 1993, 209-224.

[10] Software Engineering Institute, Standard CMMI Appraisal Method for Process Improvement, 2001 (SCAMPI, Version 1. 1).

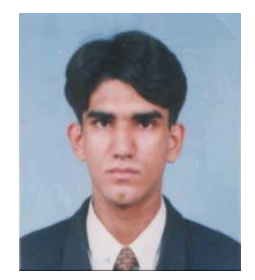

Hannan Bin Liaqat received his M. Sc. degree in Computer Science from COMSATS Institute of Information Technology, Lahore Pakistan. He is currently pursuing Ph.D degree in Department of Computer Science at Dalian University of Technology, Dalian, China.

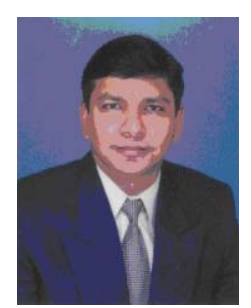

Dr. M. Rizwan Jameel Qureshi is an assistant Professor at IT Department, Faculty of Computing and Information Technology, King Abdul Aziz University, Jeddah, Saudi Arabia. He has done his Ph.D. CS (Software Process Improvement) in 2009. $\mathrm{He}$ is in the field of teaching and research since 2001. He has published twenty-two research publications and six books at national and international forums. He is teaching Software Engineering domain courses at graduate and undergraduate level from more than ten years 